\title{
Artificial ventilation during pneumoperitoneum
}

\author{
Lucia Comuzzi ${ }^{1,2}$ \\ Alysson Roncally-Carvalho ${ }^{2}$ \\ Umberto Lucangelo' \\ Walter Araujo Zin²
}

\begin{abstract}
${ }^{1}$ University of Trieste, Department of Perioperative Medicine, Intensive Care and Emergency, Cattinara Hospital, Trieste, Italy

2 Universidade Federal do Rio de Janeiro, Carlos Chagas Filho Institute of Biophysics, Rio de Janeiro, Brazil
\end{abstract}

Address for correspondence:

Walter A. Zin, MD, PhD

Universidade Federal do Rio de Janeiro

Instituto de Biofísica Carlos Chagas Filho

Av. Carlos Chagas Filho 373, Rm. G2-042

Ilha do Fundão

21941-902 Rio de Janeiro - RJ

Brazil

Phone: +55 2125641578 - Fax: +55 2122808193

E-mail: wazin@biof.ufrj.br; walter_zin@hotmail.com

\section{Summary}

Laparoscopic surgery has been increasingly used in many surgical subspecialties, due to its various post-operative benefits. On the other hand, it presents intra-operative challenges to the anesthesia management. The inflation of the abdominal cavity with carbon dioxide leads to hemodynamic changes, mechanical respiratory system derangements (increased elastance, resistance and airway pressure), augmented $\mathrm{V}^{\prime} \mathrm{CO}_{2}$, and alterations of the V'/Q' ratio and of the $\mathrm{PaCO}_{2}-\mathrm{PetCO}_{2}$ gradient. All these changes may be influenced by other factors, such as body position and baseline characteristics of the patient. To minimize the negative consequences of these modifications a protective ventilation strategy with the use of low tidal volumes and PEEP, eventually associated with recruitment maneuvers, is suggested. No ventilatory mode or anesthetic drug has been proven better than the others. It has been suggested that the use of supraglotic devices may be a safe alternative to endotracheal intubation during laparoscopic surgery. It is important that the anesthetist be aware of the complications pertaining to pneumoperitoneum to solve them quickly, paying particular attention to the patients at higher risk, such as elderly, obese, and those with cardiopulmonary disease.

KEY WORDS: pneumoperitoneum, artificial ventilation, obesity, laparoscopy, anesthesia.

\section{Introduction}

Laparoscopic surgery has been increasingly employed in various surgical subspecialties because of its innumerous benefits. These are evident during the post-operative period and result from the less important organ/tissue trauma caused by laparoscopic approaches than those triggered by open surgery. The main advantages of laparoscopic surgery are: reduction of the inflammatory and metabolic responses $(1-3)$, reduced post-operative pain and analgesic consumption (2,
Laparoscopic surgery reduces the inflammatory and metabolic responses, post-operative pain and analgesic consumption, incidence of respiratory complications, and time to recovery. 3 ), smaller incidence of respiratory complications (2), faster resolution of post-operative ileum and recovery (1). Taken together, these outcomes reduce hospital stay, promote a quicker return to normal daily activities (2-4), and reduce the cost of the treatment (4).

On the other hand, laparoscopic surgery presents some challenges regarding the intra-operative anesthesia management, since there are respiratory and hemodynamic changes pertaining to the general anesthesia itself, to the abdominal insufflation, and to the intra-operative positioning of the patient (5). These issues become even more evident in patients with cardiopulmonary disease or obesity (6).

This review focuses on the intra-operative respiratory alterations caused by laparoscopy and on the ventilatory strategies that are prone to minimize the modifications evoked by the technique.

\section{Alterations of the respiratory system}

In order to allow an adequate observation of the surgical field, laparoscopic surgery requires controlled gas insufflation into the peritoneal cavity (pneumoperitoneum). For this purpose, carbon dioxide is regularly used under a pressure of $10-15 \mathrm{mmHg}$. Naturally, respiratory issues related to mechanics and $\mathrm{CO}_{2}$ overload 
owing to the absorption of the gas into the circulation ensue.

\section{Respiratory system mechanics}

Pneumoperitoneum distends the abdominal wall and cranially displaces the diaphragm, which diminishes lung volumes, including the functional residual capacity $(\mathrm{FRC})(7,8)$, and, thus, increases the amount of atelectasis. Computed tomography scanning has also registered these alterations, showing a $1-3 \mathrm{~cm}$ cephalad diaphragmatic displacement and a higher incidence of atelectasis, especially in the dependent zones of the lung (9).

Furthermore, the high intra-abdominal pressure (Pab) increases respiratory resistance and elastance (i.e., reduces compliance). As a result, airway pressure augments $(6,7,10,12-16)$.

One should bear in mind that respiratory system elastance (Ers) equals the sum of lung (EL) and chest wall (Ew) elastances, that are both increased by pneumoperitoneum. The higher EL results from the reduced lung volumes, the more im\begin{tabular}{|l|l}
\hline Pneumoperitoneum & $\begin{array}{l}\text { portant degree of atelecta- } \\
\text { sis, the shift of blood from } \\
\text { system resistance } \\
\text { the abdomen into the thorax }\end{array}$ \\
mainly due to lung & $\begin{array}{l}\text { (17) and the surfactant al- } \\
\text { terations (7). Ew augments } \\
\text { lastic properties and } \\
\text { because of the stiffer di- } \\
\text { mechanical heteroge- } \\
\text { neities. }\end{array}$ \\
& $\begin{array}{l}\text { aphragm (7) and chest wall } \\
\text { conformational changes (6, } \\
\text { 12). }\end{array}$
\end{tabular} Some authors found that Ew increases more than $\operatorname{EL}(7,12,15,16)$. Pneumoperitoneum rises respiratory system resistance (Rrs) $(6,7$, 10-13) mainly due to lung and chest wall viscoelastic properties and mechanical heterogeneities (12). Airway resistance (Raw) remains unaltered $(7,12)$. Hence, the increase in elastance represents the main component of the larger respiratory system impedance (which depends on both Ers and Rrs) triggered by pneumoperitoneum (10).

According to Eq. 1, the increased Ers and Rrs induce larger Paw:

$\operatorname{Paw}(t)=E r s . V(t)+$ Rrs. V'(t)

where V, V' and t are volume, flow and time, respectively.

It has been demonstrated that both peak and plateau Paw are higher during pneumoperitoneum $(13,15,16)$, as shown in Figure 1. It should be stressed that Paw does not allow the identification of which respiratory system mechanical component is altered. It reflects both pulmonary and chest wall phenomena, which are measured using transpulmonary (PL) and transthoracic pressures $(\mathrm{Pw})$, respectively. To pinpoint these components, one should use the intrapleural pressure, which is more easily and safely represented by the esophageal pressure (18).

Taking into consideration that the increased Ew generates most of the additional mechanical load generated by pneumoperitoneum, most of the increased Paw is spent to overcome it (higher $\mathrm{Pw}$ ). This additional pressure is not transmitted to the lungs ( $P L$ does not change appreciably) and, thus, does not harm them. Consequently, right after the beginning of abdominal insufflation the anesthetist should establish a new set point to monitor Paw (19).

Clinically, an increase in intrathoracic pressure can diminish cardiac output (6) and trigger ventilator-induced

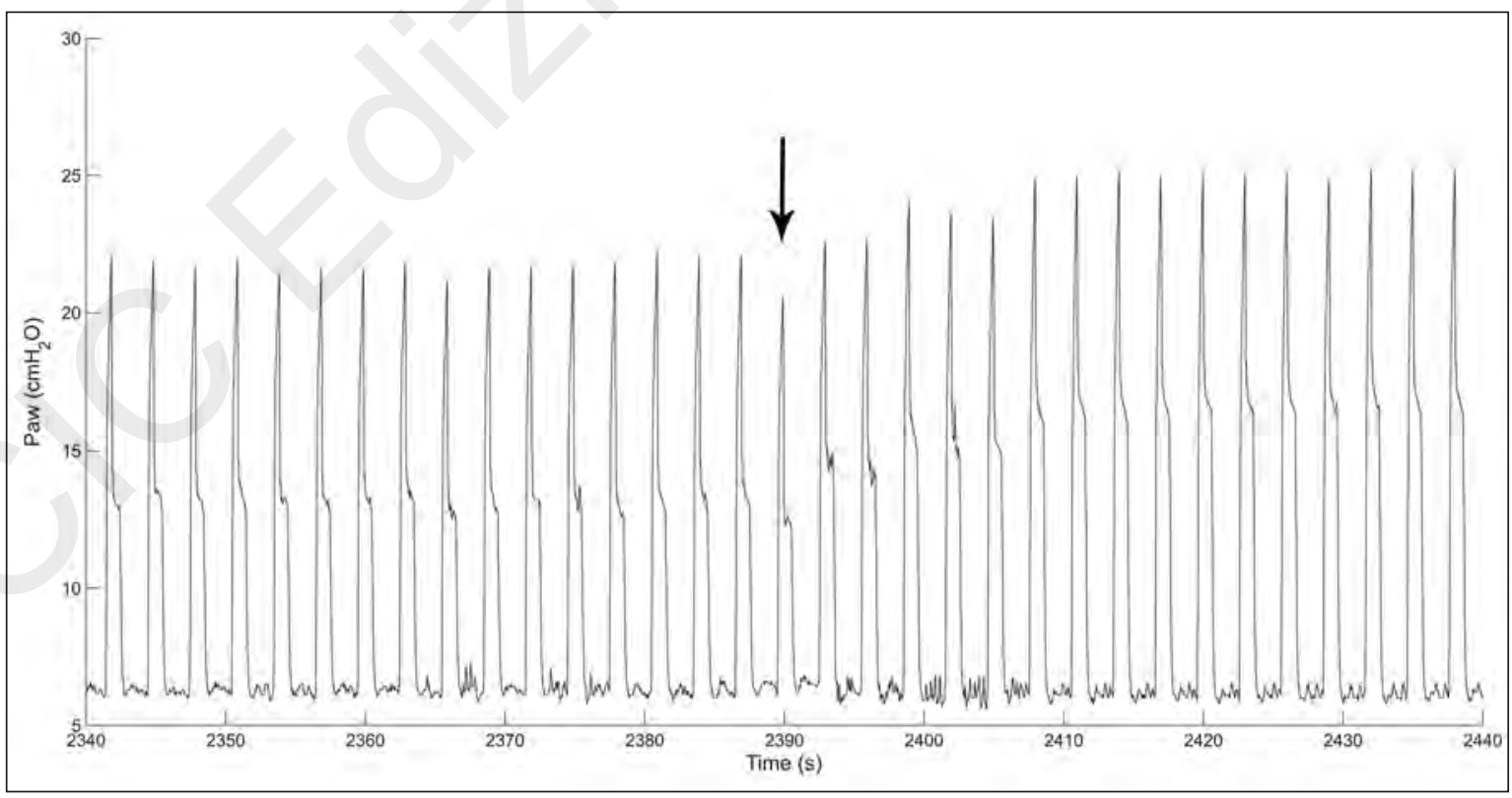

Figure 1 - Airway pressure (Paw) as a function of time in an anesthetized human being. Volume-controlled artificial ventilation was applied with a positive end-expiratory pressure of $6 \mathrm{cmH}_{2} \mathrm{O}$. At the point indicated by the arrow, $\mathrm{CO}_{2}$ was injected into the peritoneal cavity to produce a $15-\mathrm{cmH}_{2} \mathrm{O}$ intra-abdominal pressure (pneumoperitoneum). Note that both peak and plateau Paw increase afterwards. 
lung injury (VILI) (20). Although most patients can well tolerate these changes, clinically important consequences concerning the respiratory system may result in those with deranged baseline respiratory mechanics, e.g., with pneumopathies or obese (6).

The deflation of the abdominal cavity can revert all the mechanical alterations. However, there is no consensus about the timeline that describes the normalization of the parameters. Indeed, some studies state that elastance and resistance return to control values simultaneously and right after the removal of the pneumoperitoneum $(7,14)$, whereas others found that the alterations, particularly elastance, last longer (10).

\section{V'/Q' ratio and gas exchange \\ Oxygen}

During general anesthesia a progressive impairment of gas exchange occurs, which may be explained by a few mechanisms, such as small airways collapse (21) and atelectasis. These phenomena may jeopardize ventilation/perfusion relationship (V'/Q') and create shunt (22), thus reducing oxygenation mainly in elderly (23) and obese patients $(7,11)$. As aforementioned, atelectasis is even worse in the presence of pneu-

The fall in arterial
partial pressure of
oxygen correlates
with body mass, and
not with the mecha-
nical alterations in-
duced by pneumo-
peritoneum.
moperitoneum and one would expect a more important impairment of oxygenation than during general anesthesia $(24,25)$. However, some studies indeed demonstrate that the fall in arterial partial pressure of oxygen $\left(\mathrm{PaO}_{2}\right)$ is correlated solely with body mass and not with the mechanical alterations induced by pneumoperitoneum $(7,8,11)$ or decubitus (11). Furthermore, a transient increase in oxygenation and a fall in shunt $(16,26,27)$ without any change in dead space or V'/Q' have been reported $(28,29)$. Additionally, two studies in pigs using single-positron emission computed tomography (SPECT) and electrical impedance tomography (EIT) demonstrated that the insufflation of the abdominal cavity shifts ventilation $(27,30)$ and perfusion (27) from the dependent to the non-dependent region of the lungs. Moreover, the change of the latter is more important than that of the former, thus improving V'/Q' (27). These findings could possibly be explained by an increase in arterial blood pressure resulting from the higher Pab (16), a more efficient hypercapnia-induced hypoxic pulmonary vasoconstriction (27), or a reduced perfusion of the atelectatic areas induced by the increased intrathoracic pressure (26).

\section{Carbon dioxide}

Pneumoperitoneum elevates both the $\mathrm{CO}_{2}$ level in the organism and the $\mathrm{CO}_{2}$ production $\left(\mathrm{V}^{\prime} \mathrm{CO}_{2}\right)$. These alterations may lead to hypercapnia and respiratory acidosis $(7,28,29)$ that are more commonly found in patients with cardiopulmonary impairment (31).

The increase in $\mathrm{V}^{\prime} \mathrm{CO}_{2}$ results solely from the higher peritoneal absorption of $\mathrm{CO}_{2}$ and not from either a higher metabolic rate $(28,29,32)$ or an increased dead space $(26,27)$. The higher $\mathrm{CO}_{2}$ absorption is time-limited, generally reaching a steady-state 15-30 minutes post-insufflation $(28,33)$. It is also restrained by $\mathrm{Pab}$ : when it reaches about $10 \mathrm{mmHg} \mathrm{CO}$ absorption stabilizes, probably owing to compression of the peritoneal capillaries (32). In practice, the changes in $\mathrm{V}^{\prime} \mathrm{CO}_{2}$ found after the steady-state is reached probably result from other causes, e.g., V'/Q' mismatch, hypoventilation, or $\mathrm{CO}_{2}$ absorption by other tissues, as in subcutaneous emphysema (32) or carbothorax (34), which are complications of the pneumoperitoneum.

It should be noted that $\mathrm{CO}_{2}$ absorption is more important (40-60\% vs $10-15 \%)$ (29) and does not reach a plateau in extraperitoneal laparoscopic procedures, as pelviscopy or urologic surgery $(28,29)$. Possibly, the higher density of blood vessels in these areas and the continuous dissection of the extraperitoneal space could explain these findings $(28,29)$.

Carbon dioxide output remains elevated and is well tolerated even after the resolution of the pneumoperitoneum in patients with normal cardiorespiratory function (35). However, it can cause post-operative hypercapnia in sedated subjects or in those with cardiopulmonary disease $(31,36)$.

Clinically, the partial pressure of end-tidal $\mathrm{CO}_{2}$ (Pet$\mathrm{CO}_{2}$ ) is used to monitor the arterial partial pressure of $\mathrm{CO}_{2}\left(\mathrm{PaCO}_{2}\right)$. Even though a correlation between these two parameters has been reported during laparoscopy $(7,11)$, there is evidence that $\mathrm{PetCO}_{2}$ does not properly estimates $\mathrm{PaCO}_{2}$, especially in patients with cardiorespiratory disease $(31,37)$ and in elderly subjects (23). In both cases, the $\mathrm{PaCO}_{2}-\mathrm{PetCO}_{2}$ gradient increases unpredictably. This gradient varies interand intra-individually, since it increases with time in the same patient (5). The origin of this variation is not clear, though. Putative candidates to explain this phenomenon are: redistribution of the V'/Q' ratios throughout the lung (that occurs during anesthesia), decubitus, and the variable efficiency of the hypoxic pulmonary vasoconstriction produced by the anesthetic drugs (5, 38-40). Interestingly, the degree of atelectasis during pneumoperitoneum is associated with the $\mathrm{PaCO}_{2}$-Pet$\mathrm{CO}_{2}$ gradient, but not with the $\mathrm{PaO}_{2} / \mathrm{FiO}_{2}$ ratio (41). In conclusion, one should repeatedly monitor $\mathrm{PaCO}_{2}$ by blood gas analysis, at least in patients with compromised cardiopulmonary function (37) and eventually in the elderly.

\section{Body position}

The aforementioned parameters can undergo variations according to the intraoperative positioning of the patient. The literature presents diverging results, though. Some studies state that elastance does not vary among supine, Trendelenburg and anti-Trendelenburg positions $(10,11,14)$, which represent body postures frequently used in laparoscopic surgery, even in
Elastance does not vary among supine, Trendelenburg and anti-Trendelenburg positions, which represent body postures frequently used in laparoscopy surgery, even in obese patients. 
obese patients (11). A putative explanation for this finding stems from the fact that the diaphragm is overdistended by $\mathrm{CO}_{2}$ to a degree impossible to be modified by simply changing body position $(11,14)$. On the other hand, lung elastance and resistance may increase in Trendelenburg position (6), the beach chair position improves lung volumes, resistance and oxygenation in obese patients (16), and in obese hypertensive patients with chronic obstructive pulmonary disease similar results have been reported in anti-Trendelenburg position (42).

\section{Obese patients}

Laparoscopic bariatric surgery has been increasingly performed. In this condition, besides the challenges presented by laparoscopy itself, there are anesthesiological issues characteristic of obese patients. Under baseline conditions they present increased chest wall (43) and, possibly, pulmonary elastances $(44,45)$, reduced lung volumes (including FRC), and higher closing capacity. As a result, V'/Q' mismatch, impaired oxygenation and increased shunt (46) can be found. These pathologic conditions worsen during general anesthesia (47).

Pneumoperitoneum adds an extra burden to those promoted by general anesthesia.

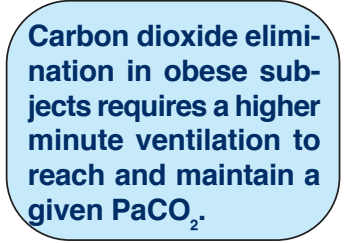
The increase in Rrs is relatively larger than that displayed by non-obese subjects, possibly because of the narrower airways secondary to the lower lung volumes (11). Elastance also increases $(16,48,49)$, but to a lesser extent than in normal weight individuals (11). Indeed, the higher baseline Pab renders the additional load generated by pneumoperitoneum a small fraction of the overall pressure (48).

Oxygenation is inversely correlated with body mass (47), and remains unaltered or improves in the presence of pneumoperitoneum (11, 16, 48, 49). Carbon dioxide elimination is not as efficient as in normal weight subjects, which requires a higher minute ventilation to reach and maintain a given $\mathrm{PaCO}_{2}$. Consequently, the control of hypercapnia poses an extra difficulty to the physician $(11,49)$.

\section{Mechanical ventilation}

\section{Protective ventilation and hypercapnia}

Protective ventilation (small tidal volumes and positive end-expiratory pressure, PEEP) has been claimed to reduce pulmonary inflammation and mortality in patients with acute respiratory distress syndrome (ARDS) (50). Protective ventilation would avoid as much as possible lung injury. In fact, it has been already proven that artificial ventilation may worsen (50) or cause VILI (51), which triggers lung inflammation (biotrauma), production of pro-inflammatory mediators, systemic inflammation, and, possibly, injures other organs (50). High tidal volumes, since they can overdistend alveoli (volu- trauma) (52), and the absence of adequate PEEP levels, which leads to cyclic alveolar opening-closing (atelectrauma) (53) constitute the probable main culprits of VILI.

A ventilatory strategy with a tidal volume of $6-8 \mathrm{ml} / \mathrm{kg}$ BW and a PEEP amounting
A tidal volume of 7 $\mathrm{ml} / \mathrm{kg}$ BW plus a 10$\mathrm{cmH}_{2} \mathrm{O}$ PEEP employed per-operatively produced a better post-operative respiratory function than a non-protective ventilation. to $6-8 \mathrm{cmH}_{2} \mathrm{O}$ used in either open or laparoscopic surgery improves post-operative respiratory function, reduces the incidence of pulmonary and extra-pulmonary complications and hospital stay in comparison with a strategy with high tidal volume and no PEEP (54). Additionally, a tidal volume of $7 \mathrm{ml} / \mathrm{kg}$ BW plus a $10-\mathrm{cmH}_{2} \mathrm{O}$ PEEP employed peroperatively (open surgery) produced a better post-operative respiratory function than a non-protective ventilation (55). A recent meta-analysis, which includes these studies, confirms that a protective ventilation strategy can decrease the development of ARDS, pulmonary infection and atelectasis, but not mortality, in previously non-injured lungs in the peri-operative period and in the intensive care unit (56). It would be interesting to perform similar studies in laparoscopic surgery.

The use of low tidal volumes predisposes to the development of hypercapnia, which is commonly present during laparoscopy. Minute ventilation must be augmented to maintain normocapnia $(33,57)$. To accomplish such goal, one should increase respiratory rate instead of tidal volume. Such setting increases the risk of developing intrinsic PEEP (PEEPi), which demands a closer control by the anesthetist. Such risk is further increased by pneumoperitoneum that elevates $\operatorname{Rrs~(6,~}$ $7,10-13$ ) especially in obese (11), COPD, and elderly patients, who present a higher closing capacity. However, the quest for normocapnia is still debatable, since hypercapnia possibly plays a protective role against the development of VILI (58-60).

\section{Ventilatory modes}

There are two modes of controlled ventilation: volumecontrolled ventilation (VCV), in which the ventilator delivers a chosen tidal volume with a constant flow, and pressure-controlled ventilation (PCV), where a constant set pressure is applied with a pre-established duration. In the former and latter cases pressure and volume vary, respectively, as a function of the respiratory system mechanical properties.

During laparoscopy, PCV re-
The beneficial effect of PSV probably results from the diaphragmatic contractions that better distribute ventilation, even to normally less ventilated regions. duces peak pressure, keeps (61) or slightly diminishes (62) mean Paw, increases respiratory system dynamic compliance, and does not modify gas exchange and cardiac function $(61,62)$. One study states that in obese patients oxygenation and Paw are not influenced 
by the ventilatory mode (63), whereas another found better oxygenation, $\mathrm{pH}$ and $\mathrm{PaCO}_{2}$ in obese patients ventilated in PCV, remaining mean and plateau Paw's similar in both modes. The authors suggest that an improved V'/Q' could respond for a better gas exchange in PCV (64).

One disadvantage of PCV rests on the tidal volume variability and, hence, the impossibility of assuring a constant minute ventilation. However, some recently introduced operating room ventilators incorporate a pressure-controlled volume-assured ventilatory mode. In this case, the anesthetist sets tidal volume that is delivered under decelerating airflow and constant pressure. The ventilator automatically regulates the latter.

Increasing inspiratory duration can improve V'/Q'. A study demonstrated that the ventilation in VCV mode with an inspiratory/expiratory ratio (I:E) of $1: 1$ or $2: 1$ rises mean $\mathrm{Paw}$ and maintains oxygenation during pneumoperitoneum (65). A $5-\mathrm{cmH}_{2} \mathrm{O}$ PEEP with $\mathrm{I}: E=1: 2$ produces the same outcomes, but increases peak and plateau pressures. PEEPi was detected in some patients with augmented I:E, which could explain the better oxygenation. Furthermore, $\mathrm{CO}_{2}$ removal is improved in patients with $\mathrm{I}: \mathrm{E}=2: 1$ (65), suggesting that PEEP can increase dead space (66). It should be stressed that a high inspiratory duration should be cautiously used in patients with a slow alveolar emptying, as those with COPD.

A better oxygenation in pressure-support ventilation (PSV, in which the patient triggers tidal volume delivery) than in PCV was found in pigs with pneumoperitoneum (67). The beneficial effect of PSV probably results from the diaphragmatic contractions that better distribute ventilation, even to normally less ventilated regions (68).

Briefly, there is no net superiority among ventilatory modes. The anesthetist should in fact choose the mode that suits her/him, based on personal experience.

\section{Alveolar recruitment and PEEP}

Applied PEEP increases lung volume (8) and avoids end-expiratory airway closure (69), thus reducing atelectrauma (70). A 5- $\mathrm{cmH}_{2} \mathrm{O}$ PEEP diminishes intrapulmonary shunt and improves oxygenation in the presence of pneumoperitoneum (71). EIT confirmed that PEEP augments ventilation in the dependent lung zones during pneumoperitoneum $(30,72)$. Furthermore, the improved V' distribution may indicate that there is a less intense alveolar stretching in the nondependent lung regions (72). On the other hand, PEEP can excessively distend the

PEEP associated with recruitment maneuvers improves oxygenation and respiratory mechanics in obese patients with pneumoperitoneum. alveoli, increasing the risk of barotrauma and decreasing cardiac output, especially in hypovolemic patients, impairing V'/Q' and oxygenation $(73,74)$.

It is quite possible that the individual response to PEEP results from the balance be- tween its positive and negative outcomes. For instance, a 10- $\mathrm{cmH}_{2} \mathrm{O}$ PEEP improves oxygenation in obese subjects but not in normal weight individuals, possibly because in the former its beneficial effects overcome their negative counterparts (47).

Recruitment maneuvers (RM), which require a high Paw, aim at the reopening of atelectatic alveoli (75) that are maintained open by the subsequent use of PEEP. In normal weight and obese patients, a 10$\mathrm{cmH}_{2} \mathrm{O}$ PEEP partially overcomes the negative consequences of pneumoperitoneum because it increases FRC and diminishes Ers. Oxygenation also improves when PEEP is associated with a RM of $40 \mathrm{cmH}_{2} \mathrm{O}$ during $40 \mathrm{~s}$ (8). The fall in Ers, which is due mainly to EL (15), possibly indicates that the higher FRC results from alveolar recruitment and not from overdistension (8). These findings have been recently confirmed by the use of a RM generated by a progressive increase in the PEEP level (under PCV) until peak pressure equaled $40 \mathrm{cmH}_{2} \mathrm{O}$, followed by a $5-\mathrm{cmH}_{2} \mathrm{O}$ PEEP. Furthermore, even Ew decreases, probably because of the higher pulmonary expansion that resembles to a better extent the physiological conformation not only of the lung, but also of the chest wall (13). Additionally, PEEP can reduce Rrs because it opens and stabilizes air spaces $(13,15)$.

PEEP associated with repeated RM's improves oxygenation $(76,77)$ and respiratory mechanics in obese patients with pneumoperitoneum (77). It should be mentioned that in one study the patients required more vasopressor agents (76). Interestingly, repeated RM associated with a PEEP of $10 \mathrm{cmH}_{2} \mathrm{O}$ or the beach chair position could improve respiratory mechanics and oxygenation in the absence of pneumoperitoneum; however, the association of these maneuvers was wanted during abdominal inflation (16).

The possible reduction of central nervous system perfusion and oxygenation owing to PEEP in the presence of pneumoperitoneum raises an important issue. PEEP by itself increases central venous pressure (CVP) and reduces mean arterial pressure (MAP), whereas pneumoperitoneum alone triggers vasodilation of the encephalic blood vessels, as a result of hypercapnia, and may, thus, increase intracranial pressure (78), especially in Trendelenburg position (79). Recently, however, it has been reported that a $10-\mathrm{cmH}_{2} \mathrm{O}$ PEEP and Trendelenburg position maintain cerebral oxygenation even in the presence of reduced perfusion pressure (calculated as the difference between PAM and PVC) during pneumoperitoneum (80).

In summary, it seems that PEEP represents a valid tool to maintain oxygenation during pneumoperitoneum. Particularly in obese patients, it should be associated with recruitment maneuvers.

\section{Inspiratory oxygen fraction $\left(\mathrm{FiO}_{2}\right)$}

It is well known that a $\mathrm{FiO}_{2}$ equal to 1 is associated with the quick installation of atelectasis and a worsening of intrapulmonary shunt during general anesthesia in patients with normal lungs (81). Additionally, an experimental study demonstrated an exacerbation of lung damage when high tidal volumes are associated 
with a $\mathrm{FiO}_{2}$ equal to 0.5 (82). Thus, low levels of $\mathrm{FiO}_{2}$ and low tidal volumes are recommended during surgery to avoid such undesired outcomes. This rationale can possibly be cautiously extended to laparoscopic surgery for the time being, since no report was found in the literature dealing with this issue.

\section{Supraglotic devices}

Commonly, laparoscopic surgery demands muscle relaxation, intubation, and controlled ventilation. However, this surgery can also be performed with supraglotic devices under spontaneous (83), assisted (84) or controlled ventilation (85-88). Laryngeal mask airway (LMA) was proven efficient during cholecystectomy $(85,87)$ and gynecological interventions $(83,84,86$,

88). LMA's, particularly those with a conduit to allow the

Laryngeal masks ha-
ve a high oropharyn-
geal leak pressure
and can, hence, pro-
vide adequate venti-
lation during laparo-
scopy.
placement of a nasogastric tube, have a high oropharyngeal leak pressure and can, hence, provide adequate ventilation during laparoscopy $(85,87,89)$. Additionally, they induce less important upper airways post-operative pharyngolaryngeal discomfort than the tracheal tube (89), and present a very low risk of regurgitation in patients without any other risk factors under controlled ventilation (88). The latter observation raises an important issue, since it is generally accepted (90) that laparoscopy, especially in the Trendelenburg position, increases the risk of regurgitation and that LMA does not protect the airway against aspiration. Noteworthy, surgery with LMA results shorter than with tracheal tube $(83,84)$.

\section{Anesthesia}

The choice of the anesthesia procedure is undoubtedly reserved to the anesthetist. Nevertheless, isoflurane leads to a smaller $\mathrm{PaO}_{2}$ and higher $\mathrm{PaCO}_{2}$ than propofol during laparoscopic cholecystectomy (38). Possibly, the maintenance of the hypoxic pulmonary vasoconstriction by propofol may explain this finding (91). Desflurane and sevoflurane seem to exhibit the same pharmacological property of propofol (40).

Studies dealing with the role of anesthetic agents on lung inflammation produced conflicting results. Indeed, propofol yields a pro-inflammatory effect, contrasting with the halogenated anesthetics $(92,93)$. A recent work on pigs reports just the opposite (94), whereas no difference has also been described (95). In the absence of more precise data, it thus seem more appropriate that the anesthetist chooses the pharmacological agent to be used, carefully considering the hemodynamic changes produced by the anesthetics.

The neuromuscular blockers, commonly considered essential for the laparoscopic surgery, do not importantly change respiratory mechanics during pneumoperitoneum in intubated patients (15). The insertion of the trocar in spontaneously breathing patients with LMA seems to be more difficult than in intubated paralyzed subjects; however, after the placement of the tro- car, both approaches allowed a good observation of the surgical field (83).

In conclusion, laparoscopic surgery presents evident pre-operative risks besides the beneficial outcomes observed after surgery. It is imperative that the anesthetist be thoroughly aware of the possible respiratory and hemodynamic impairments and of the complications pertaining to the pneumoperitoneum to solve the undesired outcomes adequately and quickly. Finally, one must bear in mind that there are patients presenting a more important risk to develop complications and deserving a closer observation, as the elderly or obese, and those with cardiopulmonary disease.

\section{Disclosure}

Finantial support: Brazilian Council for Scientific Research, Development and Innovation (CNPq), and Rio de Janeiro State Research Supporting Foundation (FAPERJ).

\section{References}

1. Jakeways MSR, Mitchell V, Hashim IA, et al. Metabolic and inflammatory responses after open or laparoscopic cholecystectomy. British journal of surgery. 1994;81:127-131.

2. Joris J, Cigarini I, Legrand M, et al. Metabolic and respiratory changes after cholecystectomy performed via laparotomy or laparoscopy. British journal of anaesthesia. 1992;69:341-345.

3. Mealy K, Gallagher H, Barry M, Lennon F, Traynor $\mathrm{O}$, Hyland J. Physiological and metabolic responses to open and laparoscopic cholecystectomy. British Journal of surgery. 1992;79:1061-1064.

4. Grace PA, Quereshi A, Coleman J, et al. Reduced postoperative hospitalization after laparoscopic cholecystectomy. British journal of surgery. 1991;78:160-162.

5. Klopfenstein CE, Schiffer E, Pastor CM, et al. Laparoscopic colon surgery: unreliability of end-tidal CO2 monitoring. Acta Anaesthesiologica Scandinavica. 2008;52:700-707.

6. Fahy BG, Barnas GM, Flowers JL, Nagle SE, Njoku MJ. The effects of increased abdominal pressure on lung and chest wall mechanics during laparoscopic surgery. Anesthesia \& Analgesia. 1995;81:744-750.

7. Pelosi P, Foti G, Cereda M, Vicardi P, Gattinoni L. Effects of carbon dioxide insufflation for laparoscopic cholecystectomy on the respiratory system. Anaesthesia. 1996;51:744-749.

8. Futier E, Constantin JM, Pelosi P, et al. Intraoperative recruitment maneuver reverses detrimental pneumoperitoneum-induced respiratory effects in healthy weight and obese patients undergoing laparoscopy. Anesthesiology. 2010; 113:1310-1319.

9. Andersson LE, Bååth $M$, Thörne $A$, Aspelin $P$, Odeberg-Wernerman S. Effect of carbon dioxide 
pneumoperitoneum on development of atelectasis during anesthesia, examined by spiral computed tomography. Anesthesiology. 2005; 102:293-299.

10. Rizzotti L, Vassiliou M, Amygdalou A, et al. Respiratory system mechanics during laparoscopic cholecystectomy. Respiratory medicine. 2002;96: 268-274.

11. Sprung J, Whalley DG, Falcone T, Warner DO, Hubmayr RD, Hammel J. The impact of morbid obesity, pneumoperitoneum, and posture on respiratory system mechanics and oxygenation during laparoscopy. Anesthesia \& Analgesia. 2002;94: 1345-1350.

12. Moreira LF, Gobbi CF, Feijoo M, Rocco PR, Zin WA. Respiratory mechanics and morphometric changes during pneumoperitoneum in normal rats. European Respiratory Journal. 1997;10: 13211326.

13. Cinnella G, Grasso S, Spadaro S, et al. Effects of recruitment maneuver and positive end-expiratory pressure on respiratory mechanics and transpulmonary pressure during laparoscopic surgery. Anesthesiology. 2013;118:114-122.

14. Rauh R, Hemmerling TM, Rist M, Jacobi KE. Influence of pneumoperitoneum and patient positioning on respiratory system compliance. Journal of clinical anesthesia. 2001;13:361-365.

15. Maracajá-Neto LF, Verçosa N, Roncally AC, Giannella A, Bozza FA, Lessa MA. Beneficial effects of high positive end-expiratory pressure in lung respiratory mechanics during laparoscopic surgery. Acta Anaesthesiologica Scandinavica. 2009;53: 210-217.

16. Valenza F, Vagginelli F, Tiby A, et al. Effects of the beach chair position, positive end-expiratory pressure, and pneumoperitoneum on respiratory function in morbidly obese patients during anesthesia and paralysis. Anesthesiology. 2007;107:725-732.

17. Hedenstierna G, Strandberg A, Brismar B, Lundquist $\mathrm{H}$, Svensson $\mathrm{L}$, Tokics L. Functional residual capacity, thoracoabdominal dimensions, and central blood volume during general anesthesia with muscle paralysis and mechanical ventilation. Anesthesiology. 1985;62:247-254.

18. Zin WA, Milic-Emili J. Esophageal pressure measurement. Principles and practice of intensive care monitoring New York: McGraw-Hill. 1998545-718.

19. Valenza F, Chevallard G, Fossali T, Salice V, Pizzocri M, Gattinoni L. Management of mechanical ventilation during laparoscopic surgery. Best Practice \& Research Clinical Anaesthesiology. 2010; 24:227-241.

20. Marini JJ, Ravenscraft SA. Mean airway pressure: physiologic determinants and clinical importance-Part 2: Clinical implications. Crit Care Med. 1992;20:1604-1616.

21. Bergman NA, Tien YK. Contribution of the closure of pulmonary units to impaired oxygenation during anesthesia. Anesthesiology. 1983; 59:395-401.

22. Hedenstierna G, Tokics L, Strandberg A, Lundquist $\mathrm{H}$, Brismar $\mathrm{B}$. Correlation of gas exchange impairment to development of atelectasis during anaesthesia and muscle paralysis. Acta Anaesthesiol Scand. 1986;30:183-191.

23. Takahata O, Kunisawa T, Nagashima M, et al. Effect of age on pulmonary gas exchange during laparoscopy in the Trendelenburg lithotomy position. Acta anaesthesiologica scandinavica. 2007; 51:687-692.

24. Duggan M, Kavanagh BP. Atelectasis in the perioperative patient. Curr Opin Anaesthesiol. 2007;20:37-42.

25. McDermott JP, Regan MC, Page R, et al. Cardiorespiratory effects of laparoscopy with and without gas insufflation. Arch Surg. 1995;130: 984-988.

26. Andersson L, Lagerstrand L, Thörne A, Sollevi A, Brodin L, Odeberg-Wernerman S. Effect of CO2 pneumoperitoneum on ventilation-perfusion relationships during laparoscopic cholecystectomy. Acta anaesthesiologica scandinavica. 2002;46: 552-560.

27. Strang CM, Fredén F, Maripuu E, Hachenberg T, Hedenstierna G. Ventilation-perfusion distributions and gas exchange during carbon dioxidepneumoperitoneum in a porcine model. British journal of anaesthesia. 2010;105:691-697.

28. Mullet CE, Viale JP, Sagnard PE, et al. Pulmonary $\mathrm{CO} 2$ elimination during surgical procedures using intra-or extraperitoneal CO2 insufflation. Anesthesia \& Analgesia. 1993;76:622-626.

29. Streich B, Decailliot F, Perney C, Duvaldestin P. Increased carbon dioxide absorption during retroperitoneal laparoscopy. British journal of anaesthesia. 2003;91:793-796.

30. Meier T, Leibecke T, Eckmann C, et al. Electrical impedance tomography: changes in distribution of pulmonary ventilation during laparoscopic surgery in a porcine model. Langenbecks Arch Surg. 2006;391:383-389.

31. Wittgen $\mathrm{CM}$, Andrus $\mathrm{CH}$, Fitzgerald SD, Baudendistel LJ, Dahms TE, Kaminski DL. Analysis of the hemodynamic and ventilatory effects of laparoscopic cholecystectomy. Arch Surg. 1991; 126:997-1000; discussion 1000.

32. Lister DR, Rudston-Brown B, Warriner CB, McEwen J, Chan M, Walley KR. Carbon dioxide absorption is not linearly related to intraperitoneal carbon dioxide insufflation pressure in pigs. Anesthesiology. 1994;80:129-136.

33. Tan PL, Lee TL, Tweed WA. Carbon dioxide absorption and gas exchange during pelvic laparoscopy. Canadian journal of anaesthesia. 1992;39:677-681.

34. Joris JL, Chiche J-D, Lamy ML. Pneumothorax during laparoscopic fundoplication: diagnosis and treatment with positive end-expiratory pressure. Anesthesia \& Analgesia. 1995;81:993-1000.

35. Kazama T, Ikeda K, Kato T, Kikura M. Carbon dioxide output in laparoscopic cholecystectomy. British journal of anaesthesia. 1996;76:530-535.

36. Fitzgerald SD, Andrus $\mathrm{CH}$, Baudendistel LJ, Dahms TE, Kaminski DL. Hypercarbia during carbon dioxide pneumoperitoneum. Am J Surg. 1992;163:186-190. 
37. Neudecker J, Sauerland S, Neugebauer E, et al. The European Association for Endoscopic Surgery clinical practice guideline on the pneumoperitoneum for laparoscopic surgery. Surg Endosc. 2002;16:1121-1143.

38. Gehring H, Kuhmann K, Klotz KF, et al. Effects of propofol vs isoflurane on respiratory gas exchange during laparoscopic cholecystectomy. Acta Anaesthesiol Scand. 1998;42:189-194.

39. Karzai W, Haberstroh J, Priebe HJ. The effects of increasing concentrations of desflurane on systemic oxygenation during one-lung ventilation in pigs. Anesth Analg. 1999;89:215-217.

40. Lesitsky MA, Davis S, Murray PA. Preservation of hypoxic pulmonary vasoconstriction during sevoflurane and desflurane anesthesia compared to the conscious state in chronically instrumented dogs. Anesthesiology. 1998;89: 1501-1508.

41. Strang CM, Hachenberg T, Fredén F, Hedenstierna G. Development of atelectasis and arterial to end-tidal PCO2-difference in a porcine model of pneumoperitoneum. British journal of anaesthesia. 2009;103:298-303.

42. Salihoglu Z, Demiroluk S, Dikmen Y. Respiratory mechanics in morbid obese patients with chronic obstructive pulmonary disease and hypertension during pneumoperitoneum. European journal of anaesthesiology. 2003;20:658-661.

43. Luce JM. Respiratory complications of obesity. Chest. 1980;78:626-631.

44. Ray CS, Sue DY, Bray G, Hansen JE, Wasserman K. Effects of obesity on respiratory function. The American review of respiratory disease. 1983;128:501-506.

45. Suratt Paulm, Wilhoit Stephenc, Hsiao Henrys, Atkinson Richardl, Rochester Dudleyf. Compliance of chest wall in obese subjects. Journal of Applied Physiology. 1984;57:403-407.

46. Hedenstierna G, Santesson J. Breathing mechanics, dead space and gas exchange in the extremely obese, breathing spontaneously and during anaesthesia with intermittent positive pressure ventilation. Acta Anaesthesiologica Scandinavica. 1976;20:248-254.

47. Pelosi P, Ravagnan I, Giurati G, et al. Positive end-expiratory pressure improves respiratory function in obese but not in normal subjects during anesthesia and paralysis. Anesthesiology. 1999;91:1221-1231.

48. Dumont L, Mattys M, Mardirosoff C, Vervloesem $\mathrm{N}$, Alle JL, Massaut J. Changes in pulmonary mechanics during laparoscopic gastroplasty in morbidly obese patients. Acta anaesthesiologica scandinavica. 1997;41:408-413.

49. Nguyen NT, Anderson JT, Budd M, et al. Effects of pneumoperitoneum on intraoperative pulmonary mechanics and gas exchange during laparoscopic gastric bypass. Surgical Endoscopy And Other Interventional Techniques. 2004;18:64-71.

50. Ventilation with lower tidal volumes as compared with traditional tidal volumes for acute lung injury and the acute respiratory distress syndrome. The
Acute Respiratory Distress Syndrome Network. N Engl J Med. 2000;342:1301-1308.

51. Neto AS, Cardoso SO, Manetta JA, et al. Association between use of lung-protective ventilation with lower tidal volumes and clinical outcomes among patients without acute respiratory distress syndrome: a meta-analysis. Jama. 2012;308:16511659.

52. Dreyfuss D, Soler P, Basset $G$, et al. High inflation pressure pulmonary edema: respective effects of high airway pressure, high tidal volume, and positive end-expiratory pressure. Am Rev Respir Dis. 1988;137(5):1159-1164.

53. Slutsky AS. Lung injury caused by mechanical ventilation. CHEST Journal. 1999;116:9S-15S.

54. Futier E, Constantin JM, Paugam-Burtz C, et al. A trial of intraoperative low-tidal-volume ventilation in abdominal surgery. $\mathrm{N}$ Engl $\mathrm{J}$ Med. 2013:369:428-437

55. Severgnini P, Selmo G, Lanza C, et al. Protective mechanical ventilation during general anesthesia for open abdominal surgery improves postoperative pulmonary function. Anesthesiology. 2013; 118:1307-1321.

56. Sutherasan Y, Vargas M, Pelosi P. Protective mechanical ventilation in the non-injured lung: review and meta-analysis. Critical Care. 2014.

57. Wahba RWM, Mamazza J. Ventilatory requirements during laparoscopic cholecystectomy. Canadian journal of anaesthesia. 1993;40:206210.

58. Broccard AF, Hotchkiss JR, Vannay C, et al. Protective effects of hypercapnic acidosis on ventilator-induced lung injury. American journal of respiratory and critical care medicine. 2001;164:802806.

59. De Smet HR, Bersten AD, Barr HA, Doyle IR. Hypercapnic acidosis modulates inflammation, lung mechanics, and edema in the isolated perfused lung. Journal of critical care. 2007;22: 305-313.

60. Sinclair SE, Kregenow DA, Lamm WJE, Starr IR, Chi EY, Hlastala MP. Hypercapnic acidosis is protective in an in vivo model of ventilator-induced lung injury. American journal of respiratory and critical care medicine. 2002;166:403-408.

61. Choi EM, Na S, Choi SH, An J, Rha KH, Oh YJ. Comparison of volume-controlled and pressurecontrolled ventilation in steep Trendelenburg position for robot-assisted laparoscopic radical prostatectomy. J Clin Anesth. 2011;23:183-188.

62. Balick-Weber CC, Nicolas P, Hedreville-Montout M, Blanchet P, Stephan F. Respiratory and haemodynamic effects of volume-controlled vs pressurecontrolled ventilation during laparoscopy: a crossover study with echocardiographic assessment. $\mathrm{Br}$ J Anaesth. 2007; 99:429-435.

63. De Baerdemaeker LE, Van der Herten C, Gillardin JM, Pattyn P, Mortier EP, Szegedi LL. Comparison of volume-controlled and pressure-controlled ventilation during laparoscopic gastric banding in morbidly obese patients. Obes Surg. 2008;18:680685. 
64. Cadi P, Guenoun T, Journois D, Chevallier JM, Diehl JL, Safran D. Pressure-controlled ventilation improves oxygenation during laparoscopic obesity surgery compared with volume-controlled ventilation. Br J Anaesth. 2008;100:709-716.

65. Kim WH, Hahm TS, Kim JA, et al. Prolonged inspiratory time produces better gas exchange in patients undergoing laparoscopic surgery: A randomised trial. Acta Anaesthesiol Scand. 2013;57: 613-622.

66. Breen PH, Mazumdar B. How does positive endexpiratory pressure decrease $\mathrm{CO}<$ sub $>2$ elimination from the lung? Respiration physiology. 1996;103:233-242.

67. Loeckinger A, Hoermann C, Keller C, Lindner KH, Kleinsasser A. Augmented spontaneous breathing and pulmonary gas exchange during pneumoperitoneum. Eur J Anaesthesiol. 2002; 19:424-427.

68. Froese $A B$, Bryan AC. Effects of anesthesia and paralysis on diaphragmatic mechanics in man. Anesthesiology. 1974;41:242-255.

69. Schibler A, Henning R. Positive end-expiratory pressure and ventilation inhomogeneity in mechanically ventilated children. Pediatric Critical Care Medicine. 2002;3:124-128.

70. Duggan M, Kavanagh BP. Pulmonary atelectasis: a pathogenic perioperative entity. Anesthesiology. 2005;102:838-854.

71. Meininger D, Byhahn C, Mierdl S, Westphal K, Zwissler B. Positive end-expiratory pressure improves arterial oxygenation during prolonged pneumoperitoneum. Acta Anaesthesiol Scand. 2005;49:778-783.

72. Karsten J, Luepschen H, Grossherr M, et al. Effect of PEEP on regional ventilation during laparoscopic surgery monitored by electrical impedance tomography. Acta Anaesthesiol Scand. 2011;55:878886.

73. Santesson J. Oxygen Transport and Venous Admixture in the Extremely Obese. Influence of Anaesthesia and Artificial Ventilation with and without Positive End-Expiratory Pressure. Acta Anaesthesiologica Scandinavica. 1976;20:387394.

74. Eriksen J, Andersen J, Rasmussen JP, Sørensen B. Effects of Ventilation with Large Tidal Volumes or Positive End-Expiratory Pressure on Cardiorespiratory Function in Anesthetized Obese Patients. Acta Anaesthesiologica Scandinavica. 1978;22: 241-248.

75. Tusman G, Böhm SH, de Anda GFV, Do Campo JL, Lachmann B. Alveolar recruitment strategy improves arterial oxygenation during general anaesthesia. British journal of anaesthesia. 1999;82:813.

76. Whalen FX, Gajic O, Thompson GB, et al. The effects of the alveolar recruitment maneuver and positive end-expiratory pressure on arterial oxygenation during laparoscopic bariatric surgery. Anesth Analg. 2006;102:298-305.

77. Almarakbi WA, Fawzi HM, Alhashemi JA. Effects of four intraoperative ventilatory strategies on res- piratory compliance and gas exchange during laparoscopic gastric banding in obese patients. $\mathrm{Br} \mathrm{J}$ Anaesth. 2009;102:862-868.

78. Cooke SJ, Paterson-Brown S. Association between laparoscopic abdominal surgery and postoperative symptoms of raised intracranial pressure. Surgical endoscopy. 2001;15:723-725.

79. Halverson A, Buchanan R, Jacobs L, et al. Evaluation of mechanism of increased intracranial pressure with insufflation. Surgical endoscopy. 1998;12:266-269.

80. Jo YY, Lee JY, Lee MG, Kwak HJ. Effects of high positive end-expiratory pressure on haemodynamics and cerebral oxygenation during pneumoperitoneum in the Trendelenburg position. Anaesthesia. 2013;68:938-943.

81. Rothen HU, Sporre B, Engberg G, Wegenius G, Hogman M, Hedenstierna $G$. Influence of gas composition on recurrence of atelectasis after a reexpansion maneuver during general anesthesia. Anesthesiology. 1995;82:832-842.

82. Sinclair SE, Altemeier WA, Matute-Bello G, Chi $E Y$. Augmented lung injury due to interaction between hyperoxia and mechanical ventilation. Critical care medicine. 2004;32:2496-2501.

83. Williams MT, Rice I, Ewen SP, Elliott SM. A comparison of the effect of two anaesthetic techniques on surgical conditions during gynaecological laparoscopy. Anaesthesia. 2003;58: 574-578.

84. Swann DG, Spens H, Edwards SA, Chestnut RJ. Anaesthesia for gynaecological laparoscopy-a comparison between the laryngeal mask airway and tracheal intubation. Anaesthesia. 1993;48: 431-434.

85. Lu PP, Brimacombe J, Yang C, Shyr M. ProSeal versus the Classic laryngeal mask airway for positive pressure ventilation during laparoscopic cholecystectomy. Br J Anaesth. 2002;88:824-827.

86. Abdi W, Amathieu R, Adhoum A, et al. Sparing the larynx during gynecological laparoscopy: a randomized trial comparing the LMA Supreme and the ETT. Acta Anaesthesiol Scand. 2010;54:141-146.

87. Belena JM, Gracia JL, Ayala JL, et al. The Laryngeal Mask Airway Supreme for positive pressure ventilation during laparoscopic cholecystectomy. J Clin Anesth. 2011;23:456-460.

88. Bapat PP, Verghese C. Laryngeal mask airway and the incidence of regurgitation during gynecological laparoscopies. Anesthesia \& Analgesia. 1997;85:139-143.

89. Abdi W, Amathieu R, Adhoum A, et al. Sparing the larynx during gynecological laparoscopy: a randomized trial comparing the LMA Supreme and the ETT. Acta Anaesthesiol Scand. 2010;54:141-146.

90. Duffy BL. Regurgitation during pelvic laparoscopy. British journal of anaesthesia. 1979;51:10891090.

91. Kellow NH, Scott AD, White SA, Feneck RO. Comparison of the effects of propofol and isoflurane anaesthesia on right ventricular function and shunt fraction during thoracic surgery. British journal of anaesthesia. 1995;75:578-582. 
92. Schilling T, Kozian A, Senturk M, et al. Effects of volatile and intravenous anesthesia on the alveolar and systemic inflammatory response in thoracic surgical patients. Anesthesiology. 2011;115: 65-74.

93. Lee JJ, Kim GH, Kim J, et al. Comparison of pulmonary morbidity using sevoflurane or propofolremifentanil anesthesia in an Ivor Lewis operation. Journal of cardiothoracic and vascular anesthesia. 2012;26:857-862.
94. Kalimeris K, Christodoulaki K, Karakitsos P, et al. Influence of propofol and volatile anaesthetics on the inflammatory response in the ventilated lung. Acta Anaesthesiologica Scandinavica. 2011;55: 740-748.

95. Kvarnström AL, Sarbinowski RT, Bengtson J, Jacobsson LM, Bengtsson AL. Complement activation and interleukin response in major abdominal surgery. Scandinavian journal of immunology. 2012;75:510-516. 